Prepared for the U.S. Department of Energy

under Contract DE-AC05-76RL01830

\title{
Characterization of a Commercial Silicon Beta Cell
}

\author{
Michael Foxe \\ James Hayes \\ Michael Mayer \\ Justin Mclntyre \\ Ciara Sivels \\ Rey Suarez
}

March 2016

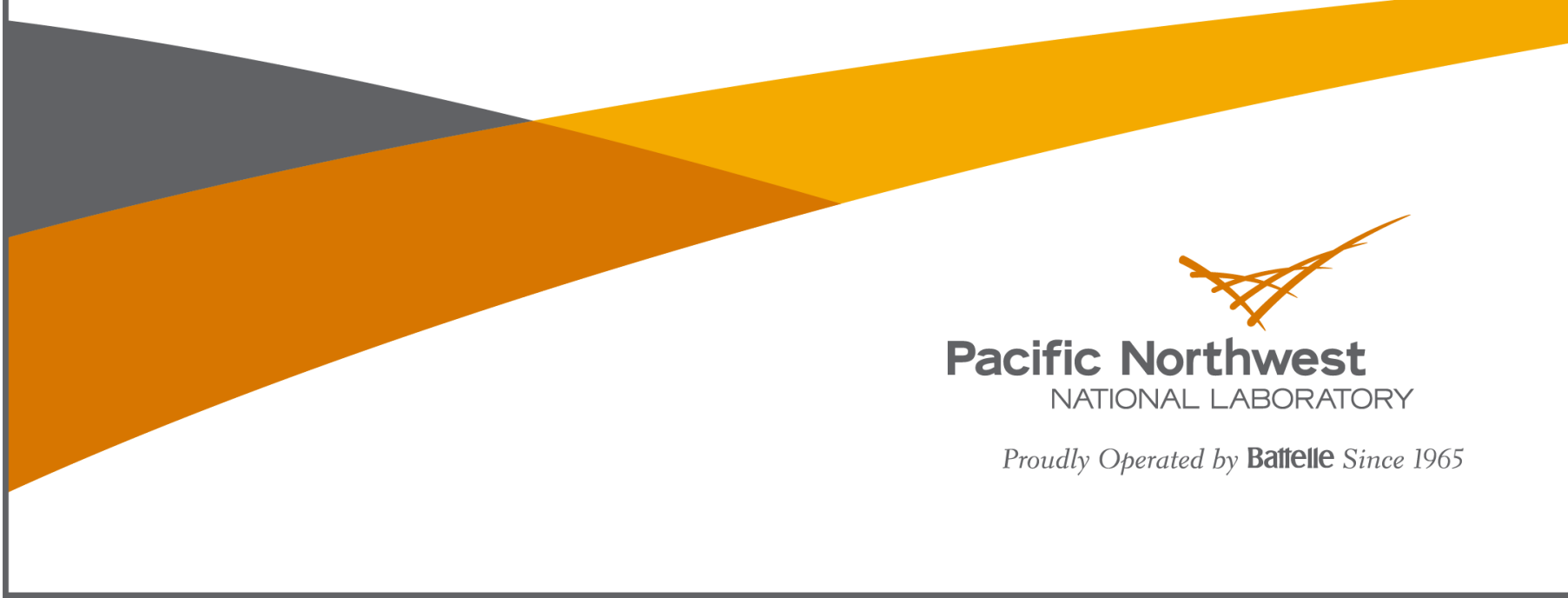




\title{
DISCLAIMER
}

This report was prepared as an account of work sponsored by an agency of the United States Government. Neither the United States Government nor any agency thereof, nor Battelle Memorial Institute, nor any of their employees, makes any warranty, express or implied, or assumes any legal liability or responsibility for the accuracy, completeness, or usefulness of any information, apparatus, product, or process disclosed, or represents that its use would not infringe privately owned rights. Reference herein to any specific commercial product, process, or service by trade name, trademark, manufacturer, or otherwise does not necessarily constitute or imply its endorsement, recommendation, or favoring by the United States Government or any agency thereof, or Battelle Memorial Institute. The views and opinions of authors expressed herein do not necessarily state or reflect those of the United States Government or any agency thereof.

\author{
PACIFIC NORTHWEST NATIONAL LABORATORY \\ operated by \\ BATTELLE \\ for the \\ UNITED STATES DEPARTMENT OF ENERGY \\ under Contract DE-AC05-76RL01830
}

Printed in the United States of America
Available to DOE and DOE contractors from the Office of Scientific and Technical Information,
P.O. Box 62, Oak Ridge, TN 37831-0062;
ph: (865) 576-8401
fax: $(865)$ 576-5728
email: reports@adonis.osti.gov

\begin{abstract}
Available to the public from the National Technical Information Service, U.S. Department of Commerce, 5285 Port Royal Rd., Springfield, VA 22161 ph: (800) 553-6847 fax: $(703) 605-6900$ email: orders@ntis.fedworld.gov online ordering: http://www.ntis.gov/ordering.htm
\end{abstract}

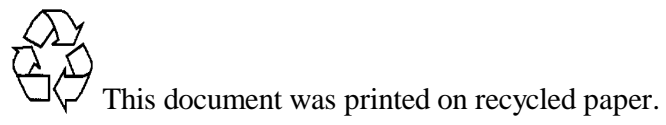





\title{
Characterization of a Commercial Silicon Beta Cell
}

\author{
Michael Foxe \\ James Hayes \\ Michael Mayer \\ Justin Mclntyre \\ Ciara Sivels \\ Rey Suarez
}

March 2016

Prepared for

the U.S. Department of Energy

under Contract DE-AC05-76RL01830

Pacific Northwest National Laboratory

Richland, Washington 99352 


\subsection{Introduction}

Silicon detectors are of interest for the verification of the Comprehensive Nuclear-Test-Ban Treaty (CTBT) due to their enhanced energy resolution compared to plastic scintillators beta cells. Previous work developing a figure-of-merit (FOM) for comparison of beta cells suggests that the minimum detectable activity (MDA) could be reduced by a factor of two to three with the use of silicon detectors ${ }^{1}$. Silicon beta cells have been developed by CEA (France) ${ }^{2}$ and Lares Ltd. (Russia) ${ }^{3}$, with the passivated implanted planar silicon beta cell (PIPSBox) developed by CEA being commercially available from Canberra for approximately $\$ 35 \mathrm{k}$, but there is still uncertainty about the reproducibility of the capabilities in the field. PNNL is developing a high-resolution beta-gamma detector system in the shallow underground laboratory, which will utilize and characterize the operation of the PIPSBox detector. Throughout this report, we examine the capabilities of the PIPSBox as developed by CEA. The lessons learned through the testing and use of the PIPSBox will allow PNNL to strategically develop a silicon detector optimized to better suit the communities needs in the future.

\subsection{Measurement Setup}

Prior to deploying the PIPSBox (Figure 1) within the low-background underground measurement system that uses HPGe detectors (Figure 2) it was tested in an aboveground setup with NaI detectors in order to verify the previously stated detector parameters. Data acquisition was performed using a PXI platform with a XIA Pixie-4 card installed. A CAEN A1422 preamplifier was used to supply the high voltage bias to and output the signal from the PIPSBox Si detectors. The complete setup can be seen in Figure 3. While the HPGe gamma efficiency cannot be measured aboveground, the beta efficiency and energy resolution were measured with the $\mathrm{NaI}$ detector setup.

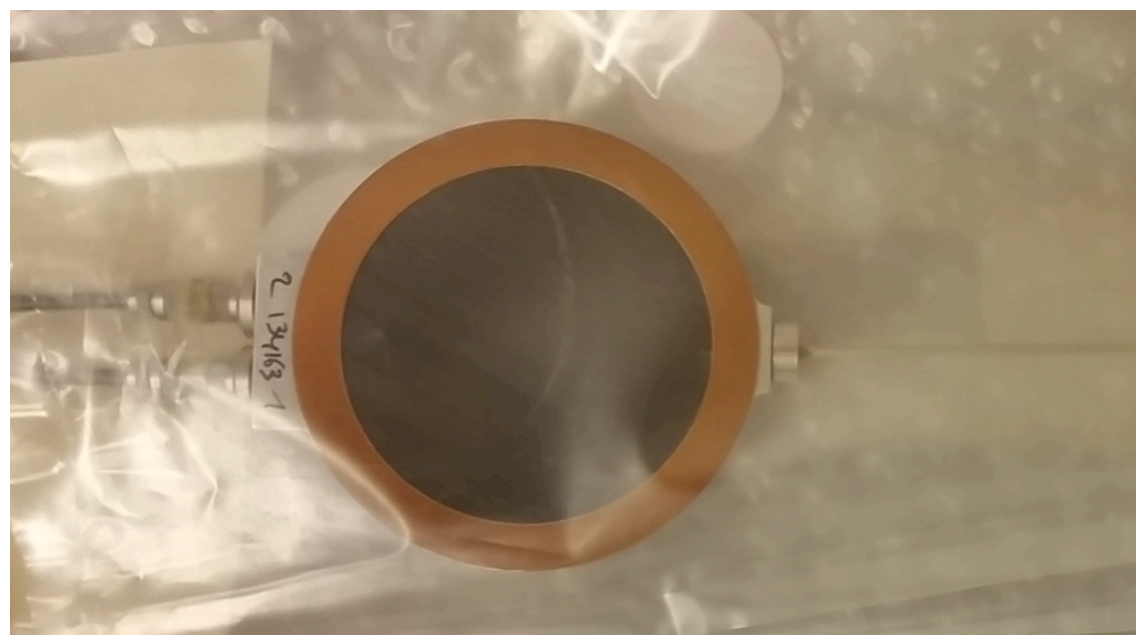

Figure 1: The PIPSBox detector ready for testing at PNNL. 


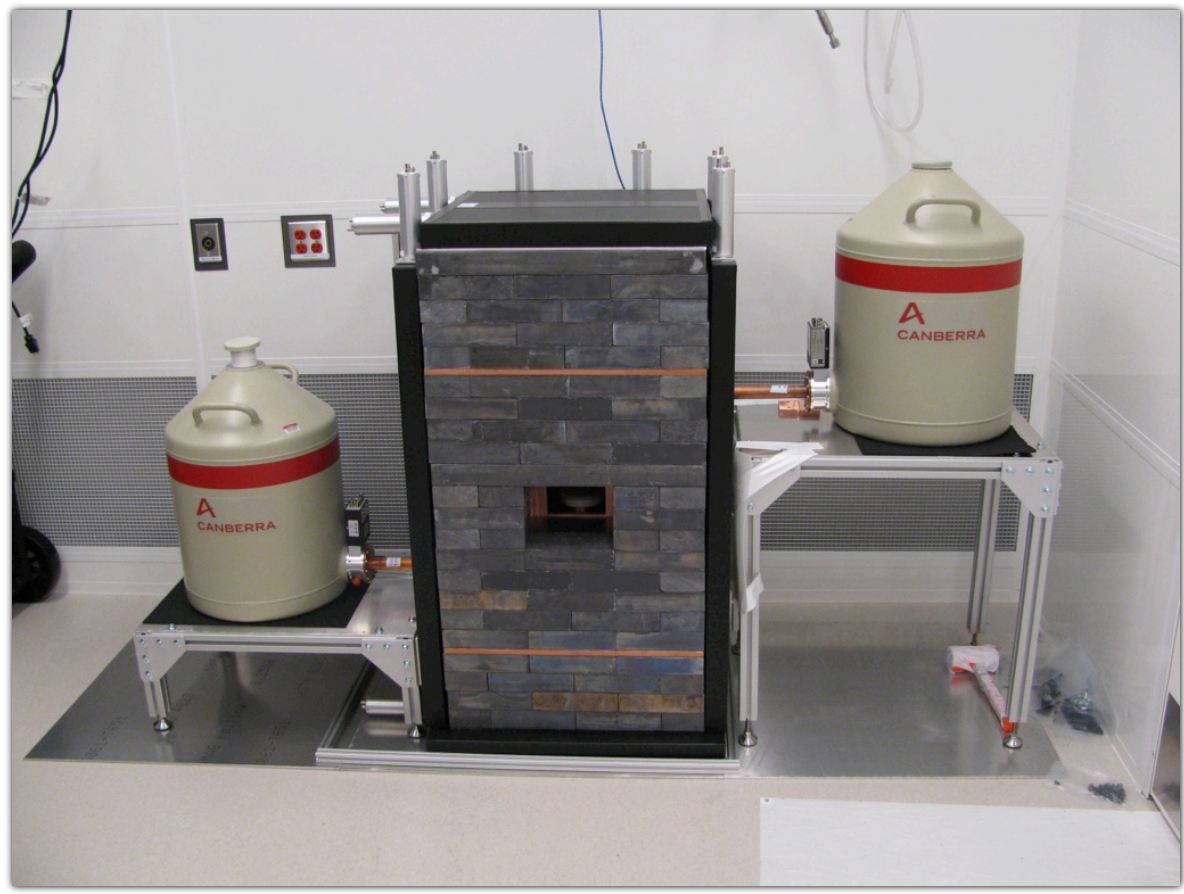

Figure 2: HPGe detectors that will act as the gamma detectors for the PIPSBox underground setup.

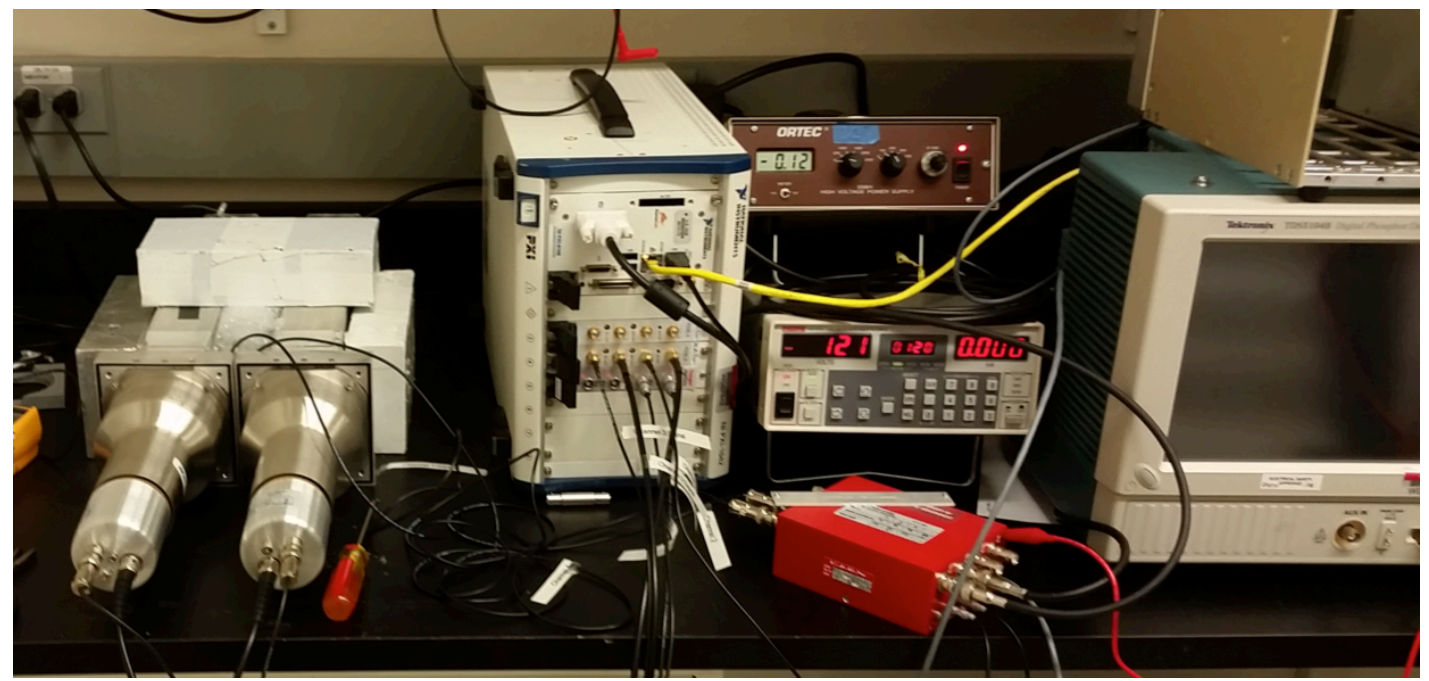

Figure 3: Aboveground measurement setup with the PIPSBox between two NaI detectors.

\subsection{Detector Capabilities}

In order to characterize a detector with the previously developed figure-of-merit (FOM), the detector efficiency, energy resolution, and memory effect need to be known ${ }^{1}$. Using the aboveground detector setup, the detector parameters were measured for the PIPSBox. 


\subsection{Energy Resolution}

The settings used with the Pixie-4 card were optimized to obtain the best energy resolution from the silicon detectors. The PIPSBox demonstrated an energy resolution of 14\% (18 keV) FWHM for the ${ }^{131 \mathrm{~m}} \mathrm{Xe} 129-\mathrm{keV}$ conversion electron, Figure 4. An energy resolution of $18 \mathrm{keV}$ is approximately $30 \%$ worse than that which was presented by $\mathrm{CEA}^{4}$. While $14 \%$ energy resolution may be enough to separate the ${ }^{131 \mathrm{~m}} \mathrm{Xe}$ and ${ }^{133 \mathrm{~m}} \mathrm{Xe}$ conversion electron peaks, it is not enough to fully separate the two conversion electrons of ${ }^{131 \mathrm{~m}} \mathrm{Xe}$, Figure 5. In addition to the energy resolution, it is desirable obtain a low threshold (minimal detector noise) capable of detecting the low-energy Auger electron events from the radioxenon isotopes, and the backscatter electron events.

With the initial high voltage supply used, the PIPSBox exhibited poor energy resolution $(\sim 30 \%)$, and it was discovered that the fluctuations of the power supply were the cause of the poor energy resolution. As silicon detectors are used in the future, it is important that the high voltage supply be stable enough to meet the needs for radioxenon detection.

$\beta$ - Coincidence

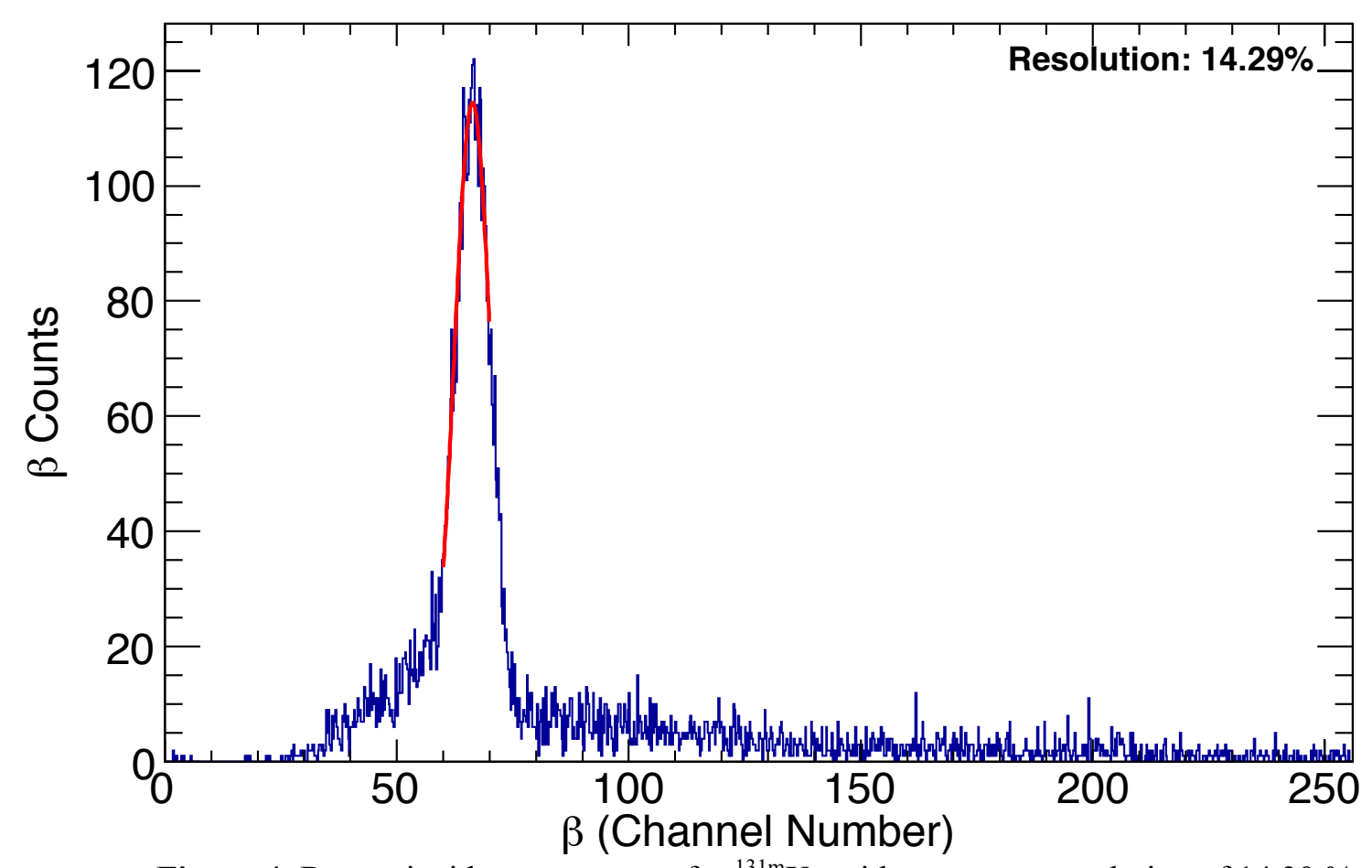

Figure 4: Beta coincidence spectrum for ${ }^{131 \mathrm{~m}} \mathrm{Xe}$ with an energy resolution of $14.29 \%$. 


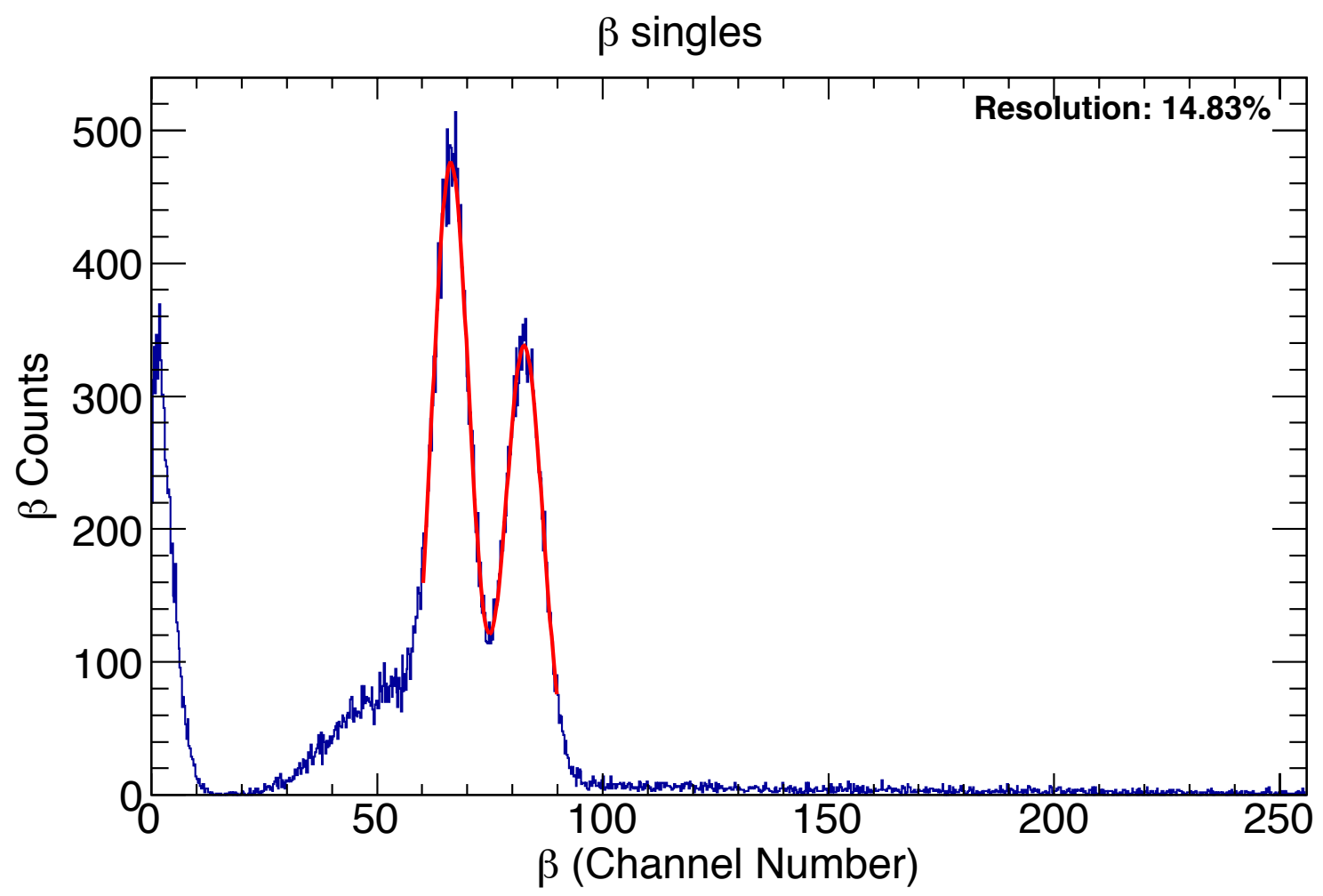

Figure 5: Beta singles spectrum for ${ }^{131 \mathrm{~m}} \mathrm{Xe}$. The energy resolution is not enough to completely separate the ${ }^{131 \mathrm{~m}}$ Xe conversion electron peaks.

\subsection{Beta Efficiency}

While the underground system detection limits could not be determined in the aboveground setup, the preliminary beta efficiency for ${ }^{131 \mathrm{~m}} \mathrm{Xe}$ were determined with the NaI gamma detectors. Due to the limited shielding used for initial testing of the PIPSBox, the calculation of the efficiency was performed using background-subtracted spectra. Figure 6 shows the overlay of the coincident gamma spectrum with that of the gamma singles from the ${ }^{131 \mathrm{~m}}$ Xe calibration spike, along with that of the background data. By taking the ratio of gamma spectra, we obtain a beta efficiency of $\sim 32 \%$. This value is approximately two-thirds of that measured by CEA with the original PIPSBox detector (44\%), and one-third of plastic scintillator beta cells $(100 \%)$. CEA states that approximately $30 \%$ of the ${ }^{131 \mathrm{~m}} \mathrm{Xe}$ events are detected with energy below the conversion electron peak due to electron backscattering ${ }^{4}$. The beta efficiency of the PNNL tested PIPSBox is expected to increase to approximately $40-45 \%$ with the optimization of the detector settings in order to lower the threshold and detect the electron backscatter events. Further refinement of detector settings should yield higher efficiency, since the lower energy tail of the ${ }^{131 \mathrm{~m}}$ Xe spectrum is absent from the current data. PNNL is currently working on the refinement process. The final beta efficiency used for each isotope will also depend on the bounds of each region-of-interest (ROI). 


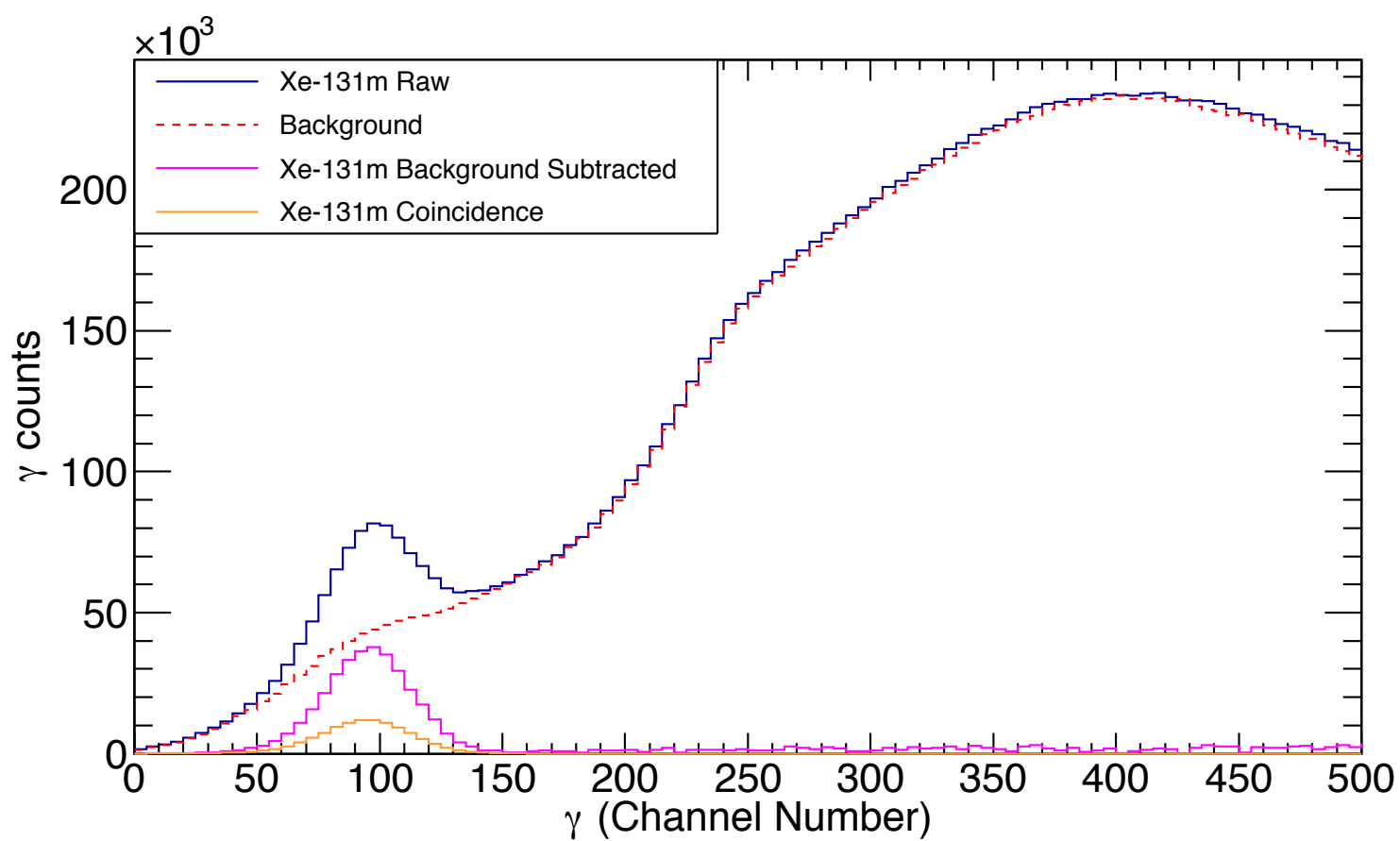

Figure 6: Beta efficiency for the PIPSBox was measured to be $32 \%$, less than the published value of $44 \%$.

\subsection{Memory Effect}

The ROI for ${ }^{131 \mathrm{~m}}$ Xe was calculated from the $3 \sigma$ Gaussian fit of the ${ }^{131 \mathrm{~m}}$ Xe peak in both the gamma and beta direction. After the ${ }^{131 \mathrm{~m}} \mathrm{Xe}$ calibration measurement, Figure 7, the memory effect was measured after two xenon potential cleanup methods. The first memory effect measurement was performed with a pump and flush routine of flushing the PIPSBox with 300 Torr of stable xenon, then pumping it down with a roughing pump. A 24-hour measurement was performed with xenon within the PIPSBox during counting, Figure 8. This procedure yielded a memory effect measurement of $0.3 \%$. The xenon was subsequently pumped out of the PIPSBox with a turbo pump for 80 minutes. The memory effect was further reduced to $0.1 \%$ with the turbo pump evacuation. Given a memory effect of $0.1 \%$ or lower, it may be reasonable to either shorten or remove the gas background run, which would allow for the sample measurement time to be increased up to 24 hours. 
$\beta-\gamma$

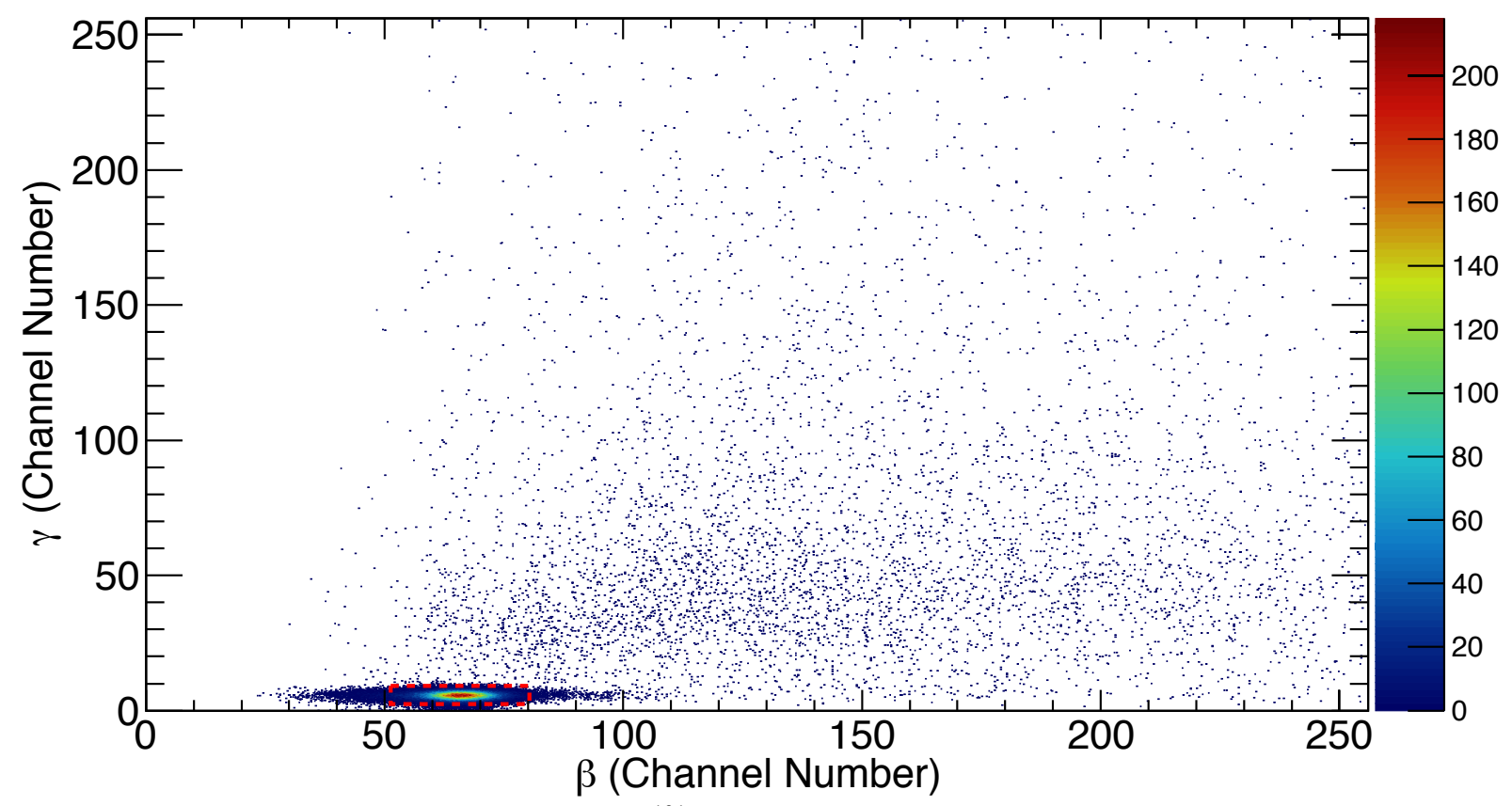

Figure 7: Beta-gamma spectrum for ${ }^{131 \mathrm{~m}} \mathrm{Xe}$, with a 3-sigma ROI drawn around the peak.

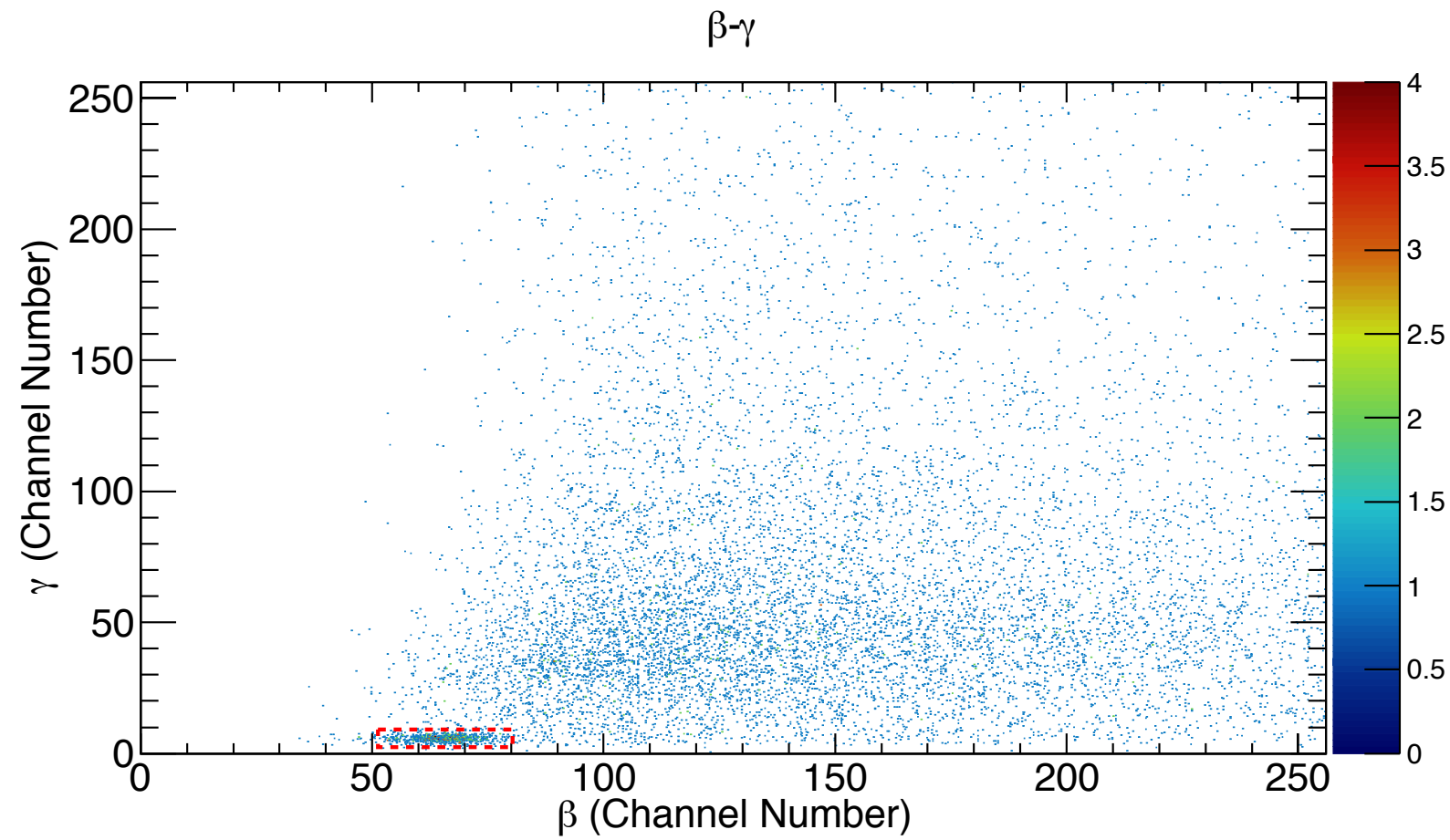

Figure 8: Memory effect ${ }^{131 \mathrm{~m}} \mathrm{Xe}$ spectrum showing a $0.3 \%$ memory effect after a pump and flush following the calibration measurement. 


\subsection{Figure-of-Merit Comparison}

Using the previously developed $\mathrm{FOM}^{1}$, the performance of the currently tested PIPSBox can be compared to plastic scintillator beta cells. The FOM used for the comparison is:

$$
\frac{100(\text { Efficiency }[\%])^{-1}(\text { Res. }[\mathrm{keV}] * 0.0025+0.025)(\text { Res. }[\mathrm{keV}] * 0.003+0.01)}{\sqrt{\frac{\text { Count Time }}{12[\mathrm{hrs}]}}}
$$

Table 1 gives the FOM for the PIPSBox with a beta efficiency of $32 \%$, an energy resolution of $18 \mathrm{keV}$, and minimal memory effect.

Table 1. FOM calculated for detector setups and parameters of interest. A lower FOM indicates a better performing detector.

\begin{tabular}{||c|c|c|c|c|c||}
\hline \hline Detector & Efficiency & Resolution & Memory Effect & Count Time & FOM \\
\hline \hline $\begin{array}{c}\text { Plastic Beta } \\
\text { Cell }\end{array}$ & $100 \%$ & $30 \mathrm{keV}$ & Yes & 12 hours & 0.2 \\
\hline $\begin{array}{c}\text { Coated Plastic } \\
\text { Beta Cell }\end{array}$ & $100 \%$ & $40 \mathrm{keV}$ & No & 24 hours & 0.18 \\
\hline $\begin{array}{c}\text { Coated Plastic } \\
\text { Beta Cell }\end{array}$ & $100 \%$ & $40 \mathrm{keV}$ & Minimal & 12 hours & 0.255 \\
\hline $\begin{array}{c}\text { PIPSBox } \\
\text { (CEA) }\end{array}$ & $50 \%$ & $10 \mathrm{keV}$ & Minimal & 24 hours & 0.128 \\
\hline $\begin{array}{c}\text { PIPSBox } \\
\text { (PNNL) }\end{array}$ & $32 \%$ & $18 \mathrm{keV}$ & Minimal & 24 hours & 0.296 \\
\hline $\begin{array}{c}\text { Si PIN Beta } \\
\text { Cell }\end{array}$ & $67 \%$ & $10 \mathrm{keV}$ & Yes & 12 hours & 0.134 \\
\hline $\begin{array}{c}\text { Optimal Si } \\
\text { Beta Cell }\end{array}$ & $100 \%$ & $10 \mathrm{keV}$ & No & 24 hours & 0.064 \\
\hline \hline
\end{tabular}

Unless the decrease in detector backgrounds expected for a silicon detector beta cell can offset the loss in detection efficiency, it appears that the overall minimal detectable concentration (MDC) of the PNNL PIPSBox may be slightly worse than that of current plastic scintillator beta cells. It is clear that for both the PIPSBox and any future silicon detector, an emphasis must be placed on maintaining high detection efficiencies in order to utilize the full benefit of the enhanced isotopic discrimination possible with the improved energy resolution of the silicon. 


\subsection{Conclusions and Future Work}

The PIPSBox shows significant improvement in energy resolution (18 keV vs $30 \mathrm{keV})$ and memory effect $(0.1 \%$ vs $5 \%)$ compared to a plastic scintillator beta cell, but suffers from poor detection efficiency $(32 \%$ vs $100 \%$ ). While the use of silicon will aid in isotope discrimination, there is room for substantial improvement in detection efficiency, and thus radioxenon sensitivity. As the PIPSBox is further tested with the HPGe detectors in the underground laboratory, the background will be reduced giving a better idea of the ultimate sensitivity for the system, both the minimum detectable activity and the isotope discrimination. In the future, effort will need to be placed on the initial design of a silicon detector in order to ensure that the detection efficiency is high enough to leverage the full capabilities of silicon with the improvements in energy resolution and memory effect.

\subsection{References}

1 Foxe, M. P., Miller, B. W., Suarez, R. \& Hayes, J. C. A Figure-of-Merit for Beta Cell Detector Characterization. 14 (Pacific Northwest National Laboratory, 2015).

2 Petit, G. L. et al. Innovative concept for a major breakthrough in atmospheric radioactive xenon detection for nuclear explosion monitoring. Journal of Radioanalytical and Nuclear Chemistry 298, 1159-1169, doi:10.1007/s10967-013-2525-8 (2013).

3 Foxe, M. P. \& McIntyre, J. I. Testing of the KRI-Developed Silicon PIN Radioxenon Detector. 36 (Pacific Northwest National Laboratory, 2015).

4 Cagniant, A. et al. Improvements of low-level radioxenon detection sensitivity by a state-of-the art coincidence setup. Applied Radiation and Isotopes 87, 48-52, doi:10.1016/j.apradiso.2013.11.078 (2014). 


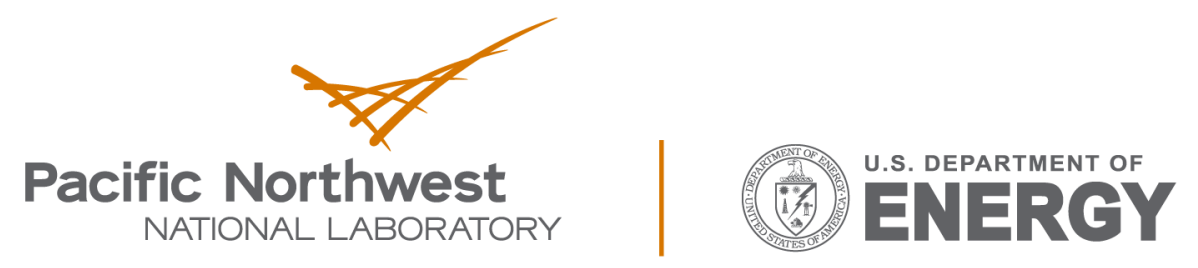

Proudly Operated by Battelle Since 1965

902 Battelle Boulevard

P.O. Box 999

Richland, WA 99352

1-888-375-PNNL (7665)

www.pnnl.gov 